\title{
Białe plamy pamięci. Nieopowiedziana historia Wielkiej Wojny w twórczości Marshy Forchuk Skrypuch
}

Chociaż w 2018 roku hucznie obchodzono setną rocznicę końca I wojny światowej, w kontekście zachodnim utożsamianej z radykalnymi zmianami dyskursywnymi, kryzysem poglądowym i epistemologicznym oraz źródłem traumy kulturowej ${ }^{1}$, pamięć o pewnych traumatycznych doświadczeniach związanych z Wielką Wojną wciąż nie zagościła w świadomości zbiorowej i oficjalnych narracjach czy choćby w wytworach kultury popularnej i literatury pięknej. A przecież, jak słusznie zauważa Marta Zielińska we wstępie do „Tekstów Drugich” poświęconych I wojnie światowej, „Oswajanie, a przez to unieszkodliwianie traum indywidualnych i zbiorowych było od zarania ludzkości jednym z najważniejszych zadań kultury"2. W kontekście ukraińskiej diaspory w Kanadzie tematami przez lata wypartymi, funkcjonującymi wyłącznie w pamięci indywidualnej ofiar i świadków, było internowanie 6 tysięcy ukraińskich imigrantów na mocy uchwalonej przez parlament w roku 1914 ustawy o prowadzeniu wojny (War Measures Act) oraz pozbawienie trzy lata później 144 tysięcy Kanadyjczyków ukraińskiego pochodzenia praw wyborczych przez ustawę o wyborach w czasie wojny (War Times Election Act) ${ }^{3}$. Mówiąc o tych kwestiach, można posłużyć

${ }^{1}$ A. Branach-Kallas, Szok Wielkiej Wojny - o traumie indywidualnej, traumie kulturowej oraz portretach gueules cassées we współczesnej literaturze brytyjskiej i francuskiej, „Teksty Drugie" 2018, nr 4, s. 17.

2 M. Zielińska, Wojna, trauma i kultura, ,Teksty Drugie” 2018, nr 4, s. 7.

3 Więcej na temat internowania Ukraińców i Kanadyjczyków ukraińskiego pochodzenia zob. B. S. Kordan, L. Y. Luciuk, Creating a Landscape: A Geography of Ukrainians in Canada, Toronto 1989; B. S. Kordan, Enemy Aliens, Prisoners of War: Internment in Canada during the Great War, Montréal 2002; L. Y. Luciuk, Ukrainians in the Making: Their Kingston Story, Kingston 1980; 
się metaforycznym określeniem „białe plamy pamięci” - terminem związanym z polityką informacyjną ukrywania i odtajniania oraz przywracaniem pamięci historycznej wydarzeń przemilczanych ${ }^{4}$. Mimo że kwestia obozów po raz pierwszy pojawiła się w świadomości publicznej w roku 1977 dzięki badaniom Lubomyra Luciuka, przez lata pozostawała tematem tabu, gdyż Kanadyjczycy nie byli gotowi na włączenie jej do narodowego dyskursu, poza tym większość związanych z nimi dokumentów została zniszczona w 1954 roku. Jak zauważa Neil Smelser,

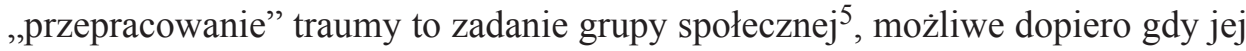
przedstawiciele uznają pewne wydarzenia za mające wpływ na zbiorową pamięć i tożsamość ${ }^{6}$. Do istnienia dwudziestu czterech obozów pracy władze Kanady oficjalnie przyznały się dopiero w roku 2005, gdy po ośmiu latach starań polityka Inky'ego Marka zatwierdzono ustawę C-331 O uznaniu internowania osób ukraińskiego pochodzenia (Bill C-331 Internment of Persons of Ukrainian Origin Recognition Act ${ }^{7}$. Trzy lata później powołano Fundusz Uznawania Kanadyjskiego Internowania w Czasie I Wojny Światowej (Canadian first world war internment recognition fund), którego zadaniem jest podtrzymywanie pamięci. Od tamtej pory rozpoczął się oficjalny proces wypełniania białych plam pamięci. Jednakże w tym przypadku jest on szczególnie trudny, gdyż większość ofiar i świadków już nie żyje, a konstruowana narracja ma charakter fragmentaryczny, oparty na postpamięci ${ }^{8}$ ich bliskich.

Doświadczenie internowania George’a Forchuka posłużyło jego wnuczce Marshy Forchuk Skrypuch do napisania pierwszych poświęconych obozom utworów dla młodego czytelnika. Problematyka ta pojawia się w jej debiutanckiej, ilustrowanej przez Michaela Martchenkę, książce obrazkowej Silver Threads (1996, pl. Srebrne nici) oraz dwóch tekstach wydanych w ramach popularnej serii „Dear Canada” (pl. „Droga Kanado”) — stylizowanej na dziennik powieści Prisoners in the Promised Land. The Ukrainian Internment Diary of Anya Soloniuk (2007, pl. Więźniowie w ziemi obiecanej. Dziennik Anyi Soloniuk z ukraińskiego internowania) i opowiadaniu świątecznym An Unexpected Memory (2009, pl. Niespodziewane wspomnienie) ${ }^{9}$. Celem niniejszego artykułu jest przybliżenie czytelnikowi tych mało znanych w Polsce i na Ukrainie utworów, które pomagają poznać

B. S. Kordan, C. Mahovsky, A Bare and Impolitic Right: Internment and Ukrainian-Canadian Redress, Montreal 2004.

${ }^{4}$ Modi memorandi: leksykon kultury pamięci, red. M. Saryusz-Wolska, R. Traba, współpr. J. Kalicka, Warszawa 2014, s. 59-60.

${ }^{5}$ N. J. Smelser, Psychological trauma and cultural trauma, [w:] Cultural Trauma and Collective Identity, red. J. C. Alexander et al., Bekeley 2004, s. 39.

6 J. C. Alexander, Trauma kulturowa i tożsamość zbiorowa, [w:] Znaczenia spoteczne. Studia z socjologii kulturowej, przeł. S. Budziej, J. Gądecki, Kraków 2010, s. 195.

7 Treść ustawy: https://openparliament.ca/bills/38-1/C-331/ [dostęp: 2.03.2019].

8 Zob. M. Hirsch, Pokolenie postpamięci, przeł. M. Borowski, M. Sugiera, „Didaskalia. Gazeta teatralna" 2011, nr 105, s. 29.

9 Motyw internowania występuje także jako wątek poboczny w młodzieżowej powieści Skrypuch Dance of the Banished, Toronto 2015. W tomie Kobzar's Children: A Century of Un- 
historię nie tylko Kanady, ale również Ukrainy i pierwszej fali emigracji, oraz przedstawienie zmiany kanadyjskiej narracji wokół obozów pracy. Pozwoli mi to pokazać, że literatura diaspory, czerpiąca z indywidualnego doświadczenia ofiar i świadków internowania, może odgrywać rolę medium wypełniającego białe plamy poprzez tworzenie pamięci kulturowej i kształtowanie w młodym odbiorcy postpamięci ${ }^{10}$.

\section{Walka o tożsamość}

Jak zauważa sama pisarka ${ }^{11}$, doświadczenie dziadka i związana z tym trauma spowodowały silną chęć asymilacji i wyparcie ukraińskiej tożsamości w pierwszym i drugim pokoleniu ofiar internowania. Przez to wiedza o Ukrainie u młodej Skrypuch była ograniczona ${ }^{12}$. Natomiast to, co znała od dziecka, to przekazywane $\mathrm{z}$ pokolenia na pokolenie poczucie wstydu ${ }^{13}$. Dopiero na studiach autorka zaczęła uczyć się kultury i historii swoich przodków, a następnie pisać pierwsze opowiadania poświęcone nieznanym w kontekście kanadyjskim wydarzeniom z dziejów Ukrainy. Panujący od lat osiemdziesiątych XX wieku memory boom ${ }^{14}$ i związane z nim zainteresowanie Holokaustem i II wojną światową doprowadziły do jednowymiarowego, negatywnego przedstawiania Ukraińców w wytworach kultury popularnej - jako antysemitów i współpracowników nazistów ${ }^{15}$. Swoją twórczością Skrypuch miała zaproponować zupełnie inną narrację, włączającą do dyskursu kanadyjskiej literatury dla dzieci i młodzieży doświadczenie ukraińskie.

Obecnie utwory pisarki poświęcone Ukrainie cieszą się sporą popularnością czytelników ${ }^{16}$ w Kanadzie i Stanach Zjednoczonych, jednak to właśnie tematyka II wojny światowej spotkała się z tak pozytywnym odbiorem i sukcesem komercyjnym. Niestety żaden z jej tekstów do tej pory nie został wydany w kraju jej przodków ${ }^{17}$. Sytuacja ta może zaskakiwać, gdyż w wielu powieściach autorka porusza tematykę wciąż nieobecną $\mathrm{w}$ ukraińskiej literaturze dziecięcej i mło-

told Ukrainian Stories (Markham 2006), którego redaktorką jest Skrypuch, dorosły czytelnik może znaleźć kilka opowiadań poruszających kwestię obozów pracy.

10 Warto w tym miejscu zauważyć, że problematyka internowania Ukraińców pojawia także w powieści młodzieżowej Lesia’s Dream (Toronto 2003) Laury Langston.

11 M. F. Skrypuch, Am I Ukrainian?, [w:] Unbound: Ukrainian Canadians Writing Home, red. L. Grekul, L. Ledohowski, Toronto 2016, s. 65-73.

12 A. Assmann, Kanon i archiwum, przeł. A. Konarzewska, [w:] eadem, Między historia a pamięcia: antologia, red. M. Saryusz-Wolska, Warszawa 2018, s. 75.

13 M. F. Skrypuch, Am I Ukrainian?, s. 65.

14 Więcej zob. Modi memorandi: leksykon..., s. 224-225.

15 M. F. Skrypuch, Am I Ukrainian?..., s. 65. Więcej na temat negatywnego przedstawiania Ukraińców w angloamerykańskich mediach zob. V. Satzewich, The Ukrainian Diaspora, London-New York 2002, s. 1-7.

$16 \mathrm{~W}$ przeciwieństwie do utworów poświęconych Armenii, takich jak The Hunger, te o doświadczeniu Ukrainy i ukraińskiej diaspory nie cieszą się popularnością wśród literaturoznawców.

17 Warto w tym miejscu zauważyć, że dwie pierwsze książki obrazkowe autorki ukazały się w ukraińskim przekładzie wyłącznie w Kanadzie - М. Ф. Скрипух, Срібні нитки, CIUS, 
dzieżowej. Ilustrowana przez Martchenkę książka obrazkowa Enough (2000, pl. Wystarczy) jako pierwszy utwór dla dzieci opowiada o Holodomorze ${ }^{18}$, powieść Hope's War (2001, pl. Wojna nadziei) — o dziewczynce, której dziadek zostaje oskarżony o współpracę z nazistami, natomiast trylogia składająca się ze Stolen Child (2010, pl. Skradzione dziecko), Making Bombs for Hitler (2012, pl. Produkujac bomby dla Hitlera) i Underground Soldier (2014, pl. Podziemny żotnierz) i najnowsza powieść Don't Tell the Enemy (2017, pl. Nie mów wrogowi) poświęcone są wielu przemilczanym aspektom II wojny światowej, takim jak ostarbeiterzy, uprowadzanie i germanizowanie ukraińskich dzieci, doświadczenie obozów pracy widziane oczami najmłodszych czy wreszcie ratowanie Żydów przez Ukraińców w Galicji.

W wypadku Ukrainy dopiero wydarzenia związane z Euromajdanem i wojną w Donbasie spowodowały pojawienie się książek, najpierw obrazkowych, później powieści poświęconych wojnie i związanej z nią traumie ${ }^{19}$. Należy podkreślić, że przyjęcie przez autorów pierwszych tego typu publikacji konwencji książki obrazkowej nie jest przypadkowe. Te multimodalne narracje rozwijają myślenie wizualne i werbalne najmłodszych czytelników, a dorosłym umożliwiają zapoznanie dziecka z problematyczną tematyką w bezpiecznym otoczeniu. Ponadto tego typu książki stanowią skarbnicę interpretacyjną, gdyż prowokują interakcje dzieci i czytających na głos opiekunów, dzięki czemu zbliżają przedstawicieli różnych pokoleń oraz stymulują podjęcie rozmów na trudne tematy ${ }^{20}$, jednocześnie prowokując transfer postpamięci. Po sugestii wydawnictwa również Skrypuch obrała ten format w swej debiutanckiej, wydanej w 1996 roku, książce Silver Threads ${ }^{21}$.

Książka opowiada o mieszkających w Bukowinie Ivanie i Annie, którzy przed wybuchem I wojny światowej, zmuszeni trudną sytuacją materialną i sytuacją polityczną, jak również zachęceni reklamą mówiącą, że Kanada „To kraina mlekiem i miodem płynąca, z nieograniczoną ilością czarnoziemu, ale niewystarczającą liczbą rolników"22, postanawiają wyemigrować z rodzinnej wsi. Motyw

Едмонтон 1996; eadem, Досить, Канадський Інститут українських студій, Альбертський університет, Едмонтон 2000.

18 Chociaż za książkę Skrypuch została uhonorowana Orderem Księżnej Olgi z rąk prezydenta Juszczenki, po jej publikacji otrzymała wiele listów z pogróżkami. Więcej na ten temat zob. A. Ulanowicz, "We are the people": The Holodomor and North American-Ukrainian diasporic memory in Marsha Forchuk Skrypuch's Enough, „Miscellanea Pottotalitariana Wratislaviensia” 2017, nr 2 (7), s. 49-72.

19 Zob. M. Świetlicki, "Oh, what a waste of army dreamers...": The revolution of dignity and war in contemporary Ukrainian picturebooks, „Filoteknos” 2018, nr 8, s. 119-130; idem, Mój tato został gwiazda. Tanatos w ukraińskiej książce obrazkowej, „Slavica Wratislaviensia” 168, 2019, s. 197-206; Т. Качак, Танатичпі мотиви у сучасній украӥнській прозі для дітей та юнацтва, „Slavica Wratislaviensia” 2019, nr 168, s. 207-218.

20 Zob. M. Świetlicki, Mój tato..., s. 197-198.

21 M. F. Skrypuch, Am I Ukrainian?, s. 65.

22 M. F. Skrypuch, Silver Threads, Toronto 2004. Książka pierwotnie ukazała się w roku 1996, jednak w niniejszym tekście korzystam z edycji z 2004 roku. Strony w obu edycjach nie są numerowane. 
ten nawiązuje do rozpoczętej w 1896 roku przez ministra Clifforda Siftona programu ściągania do Kanady ukraińskich rolników, w których widział doskonałych pracowników $^{23}$. Kuszeni 160 akrami za 10 dolarów Ukraińcy masowo zaczęli przybywać do Kanady, szczególnie po zachęcie w postaci materiałów promocyjnych wydawanych we Lwowie przez profesora Józefa Oleskowa ${ }^{24}$.

Po przyjeździe młodej pary okazuje się, że choć obiecana ziemia jest żyzna, to porastają ją liczne drzewa ${ }^{25}$. Ponadto do karczowania, a następnie orania nie ma dostępnego sprzętu. Nie zniechęca to młodego małżeństwa i wspólną pracą udaje im się uzyskać pierwsze plony i przetrwać srogą zimę. Z czasem zaczynają czuć się jak w domu. Gdy Ivan dowiaduje się o wybuchu I wojny światowej, postanawia walczyć o swoją nową ojczyznę, szczególnie biorąc pod uwagę, że w Austro-Węgrzech widzi wspólnego wroga zarówno Kanady, jak i Ukrainy. Gdy mężczyzna pragnie się zrekrutować, zostaje aresztowany ze względu na swoje pochodzenie i skazany na roboty w obozie dla internowanych. Podczas jego nieobecności Anna z trudem zmaga się z samodzielnym dbaniem o gospodarstwo, przez co po kilku latach władze grożą jej odebraniem ziemi i informują, że wojna się skończyła, a Ivan pewnie nie żyje. Motyw ten nawiązuje do polityki, wedle której internowanym Ukraińcom, takim jak dziadek Skrypuch, zabierano ziemię. Kobieta stara się jednak nie tracić wiary i dba zarówno o gospodarstwo, jak i o utrzymanie ukraińskich tradycji przypominających jej o mężu. Mimo biedy przygotowuje wigilię składającą się z prowizorycznych wariantów tradycyjnych dwunastu potraw. Niespodziewanie w dzień Bożego Narodzenia Ivan do niej wraca. Jego powrót możliwy jest dzięki występującemu w książce elementowi baśniowemu — pająkowi przywiezionemu z Bukowiny, którego Ivan, a później Anna dokarmiali okruszkami chleba, nawet gdy mieli go niewiele. W magiczny sposób zwierzę odwdzięcza się za okazaną bezinteresowną życzliwość i ozdabia choinkę tytułowymi srebrnymi nićmi, których blask pomaga Ivanowi wrócić do domu. Warto podkreślić, że na ostatniej stronie młody czytelnik znajdzie krótką bibliografię odsyłającą do materiałów umożliwiających dogłębniejsze poznanie kontekstu historycznego, jak również adnotację, że władze Kanady wciąż oficjalnie nie uznały istnienia wspomnianych obozów.

Chociaż publikacja była współfinansowana przez ukraińsko-kanadyjską Fundację Tarasa Szewczenki i u części ukraińskiej diaspory spotkała się z pozytyw-

${ }^{23}$ Więcej zob. W. Suchacka, "Za Hranetsiu” - "Beyond the Border": Constructions of identities in Ukrainian-Canadian literature, Augsburg 2019.

24 Między 1896 a 1914 rokiem do Kanady wyemigrowało 170 tysięcy Ukraińców. Zob. J. Petryshyn, L. Dzubak, Peasants in the Promised Land: Canada and the Ukrainians, 1891-1914, Toronto 1985, s. 22; więcej na temat Oleskowa zob. F. Swyripa, Ukrainian Canadians: A survey of their portrayal in English-language works, Edmonton 1978, s. 91.

${ }^{25}$ Lehr zauważa, że część Ukraińców wolała osiedlać się na terenach porastanych przez drzewa, co spowodowane było ich wcześniejszym doświadczeniem z drogim i trudno dostępnym drewnem. Zob. J. C. Lehr, Peopling the prairies with Ukrainians, [w:] Canada's Ukrainians: Negotiating an Identity, red. L. Y. Luciuk, S. Hryniuk, Toronto 1991, s. 30-52. 
nym odbiorem, niektórzy jej przedstawiciele zarzucali autorce, która nie mówi biegle po ukraińsku, że nie jest dostatecznie „prawdziwą Ukrainką,"26, by móc pisać o doświadczeniu internowania. Jak zauważa Dominick LaCapra, „pojęcie doświadczenia często okazuje się czarną skrzynką lub maksymalnie pojemnym i wszystko ogarniającym pojęciem, które pozostaje nieokreślone, ponieważ ten, kto czegoś doświadczył, zakłada, że wie, co to pojęcie oznacza"27. Inni z kolei uważali powracanie do traumatycznego, wypieranego przez lata, tematu obozów pracy za wstydliwe i nieodpowiednie, szczególnie biorąc pod uwagę, że do 2005 roku ich istnienie nie było oficjalnie uznane przez kanadyjski parlament. Z krytyką spotkały się także tradycyjne ilustracje Martchenki, szczególnie pomyłkowe wykorzystanie radzieckiej czapki na głowie jednego z bohaterów.

\section{Zmiana dyskursu}

Po wydaniu sześciu innych książek Skrypuch powróciła do tematu internowania, jednak tym razem w odmiennej sytuacji politycznej. W 2007 roku została zaproszona do współpracy w ramach popularnej serii „Dear Canada” (odpowiednik amerykańskiej „Dear America”28), w której ukazują się powieści pisane w formie dzienników dziewcząt doświadczających ważnych w historii Kanady, a często zapomnianych wydarzeń. Warto podkreślić, że w tym wypadku ukraińska diaspora została włączona do mainstreamowej narracji o kanadyjskiej świadomości narodowej. Seria skierowana jest do dzieci w wieku szkolnym i znaleźć ją można w większości kanadyjskich bibliotek (w dwóch wersjach językowych: angielskiej i francuskiej). Formuła każdego tomu jest podobna ${ }^{29}$ — to pisany przez podlotka pamiętnik, na którego okładce nie ma nazwiska autora, tylko imię protagonistki. Narracja przedstawia perspektywę uczestniczki wielu wydarzeń i bezpośredniego świadka innych, jedynie w epilogu włączony zostaje głos dorosłego — narratora tożsamego z autorem, który na kilku stronach zapoznaje czytelnika z dalszymi losami bohaterów. Do większości książek, tak jak do pamiętnika Anyi Soloniuk, dołączone są mapy, zdjęcia ${ }^{30}$ oraz krótki zarys historyczny mówiący

26 Ibidem.

27 D. LaCapra, Doświadczenie i tożsamość, [w:] idem, Historia w okresie przejściowym. Doświadczenie, tożsamość, teoria krytyczna, przeł. K. Bojarska, Kraków 2009, s. 55.

28 Więcej na temat serii „Dear America” zob. B. Lefebvre, Nationalism, nostalgia, and intergenerational girlhood. Textual and ideological extensions to Laura Ingalls Wilder's Little House, [w:] Children and Cultural Memory in Texts of Childhood, red. H. Snell, L. Hutchison, New York-London 2014, s. 47-65; A. Hubler, Girl power and history in the Dear America series books, „Children's Literature Association Quarterly” 2000, nr 25 (3), s. 98-106.

${ }^{29}$ K. Bell, Behind the blackout curtains: Female focalization of Atlantic Canada in the Dear Canada series of historical fiction, „Children's Literature in Education” 2018, nr 49, s. 163. Zob. też C. Carpenter, In our own image: The child, Canadian culture and our future, „Children's Folklore Review" 2003, nr 25 (1-2), s. 47-73.

30 Obecność zdjęć ma na celu przybliżenie czytelnikowi pamięci o opisywanych w każdym tomie wydarzeniach. Jak zauważa Hirsch, „Fotografia to praktyka »inskryptywna« (archiwalna), 
o wydarzeniach opisanych w dzienniku. W przypadku książki Skrypuch oprócz mapy Ukrainy oraz zdjęć obozu Spirit Lake z 1914 roku i współczesnego pomnika upamiętniającego ofiary dodany jest również glosariusz z terminami, które mogą być niezrozumiałe dla kanadyjskiego czytelnika. Obecność Skrypuch w tej serii świadczy o zmianie dyskursu, uznaniu nie tylko przez Kanadę, lecz także kanadyjskich Ukraińców internowania za istotny element budowania kanadyjskiej tożsamości narodowej ${ }^{31}$.

Na czerwonej okładce obok tytułu czytelnik odnajdzie zdjęcie dziewczynki, a na karcie tytułowej informację, że dziennik należy do Anyi Soloniuk pochodzącej ze wsi Horoshova w Austo-Węgrzech, wraz z datą - 13 kwietnia 1914 roku. Przed pierwszym wpisem zamieszczono list z Montrealu od ojca dwunastoletniej dziewczynki, w którym przesyła jej życzenia imieninowe oraz dziennik mający jej pomóc w zapisaniu wspomnień związanych z opuszczeniem wsi i podróżą do Kanady. Prawie każdy wpis Anya zaczyna od bezpośredniego zwrotu do pamiętnika, kilkukrotnie odnajdujemy rysunki bohaterki, urwane wpisy, poprawione słowa. Ten typ narracji powoduje, że młody czytelnik może poczuć bliższy związek $z$ bohaterką i opowiadaną przez nią historią. Dowiadujemy się, że Anya wyjeżdża ze wsi wraz z mamą, babcią i bratem, przedtem jednak spisuje osoby i rzeczy, za którymi będzie tęsknić, jak również oczekiwania, które ma w związku z Kanadą. W przeciwieństwie do Silver Threads w dzienniku Anyi mamy do czynienia z doświadczeniem migracji do wielkiego miasta. Jak później tłumaczy dziewczynka, jej ojciec został okradziony i nie mógł wyruszyć w poszukiwaniu 160 akrów ziemi, został jednak zatrudniony w fabryce. Podczas wyczerpującej dwutygodniowej podróży morskiej Anya spotyka Irynę, której tato wyruszył wcześniej i ma w Kanadzie gospodarstwo. To dzięki późniejszej korespondencji z dziewczynką w pamiętniku Anyi znajduje się miejsce dla dziadka autorki, tutaj sąsiada Iryny.

Sporą część książki poświęcono doświadczeniu budowania kanadyjsko-ukraińskiej tożsamości narodowej. Anya i jej rodzina wciąż kultywują własne tradycje, jednak stopniowo starają się zasymilować, szczególnie ze względu na doświadczoną dyskryminację. Ubiór (chustki), fryzury (warkocze) czy nawet przyzwyczajenia żywieniowe (cebula i czosnek) Soloniuków spotykają się z niechęcią Kanadyjczyków. Początkowo ojciec dziewczynki nawet nie chce pozwolić żonie podtrzymywać tradycji religijnych, co spotyka się z jej wyraźnym sprzeciwem - w rodzinie Soloniuków to kobiety są odpowiedzialne za przekazywanie zwyczajów i pamięci kulturowej. Mama znajduje pracę jako służąca u zamożnych Kanadyjczyków, babcia i młodszy brat zostają w domu, a Anya trafia do szkoły, w której oprócz codziennej dyskryminacji ze strony kanadyjskich dziewcząt i nauczycieli spotyka się też z sympatią i wsparciem innych Ukrainek, zaprzyjaźnia się z Irlandką, jak również biedniejszymi Kanadyjkami. Skrypuch demitologizuje Kanadę jako krainę

która zachowuje wymiar inkorporatywny (ucieleśniony): niczym dokumenty archiwalne, przechowując reszki przeszłości” - eadem, Pokolenie postpamięci..., s. 29.

31 Więcej na temat tożsamości narodowej Kanadyjczyków ukraińskiego pochodzenia zob. W. Suchacka, "Za Hranetsiu”... 
obfitości, tytułową ziemię obiecaną, jednak warto podkreślić, że jej nie demonizuje, a oprócz odrzucenia i nienawiści bohaterowie doświadczają sympatii i wsparcia. Nawet $\mathrm{w}$ trakcie internowania protagonistka stwierdza, że i tak jest wdzięczna, że żyje — w swojej zbombardowanej wiosce nie miałaby szans przetrwać. Gdy rodzinie Anyi powoli udaje się asymilować, a Kanadę nazywają nowym domem, wybucha I wojna światowa i wprowadzona zostaje Ustawa o prowadzeniu wojny. Ojciec i matka dwunastolatki tracą pracę i niespodziewanie jedynym żywicielem rodziny zostaje protagonistka, która wbrew woli ojca zaczęła dorabiać w fabryce. Umożliwiły jej to zdolności szycia i haftowania przekazane przez matkę.

Warto podkreślić, że w całym pamiętniku wyraźnie widać perspektywę kobiecą. Dziewczynka dowiaduje się o sufrażystkach, sympatyzuje z nimi, obserwuje polityków i mężczyzn i zaczyna wierzyć w prawa głosu dla wszystkich kobiet, również tych z niższych warstw społecznych. Dziennik zaznajamia czytelników nie tylko z historią emigracji i internowania, przemilczaną częścią dziedzictwa Ukrainy i Kanady, ale także z nieopowiedzianą herstory. Utożsamiane z kobiecością i ukraińskością umiejętności wyszywania pozwalają rodzinie Anyi przetrwać najpierw po stracie przez rodziców pracy, później w obozie i — jak dowiadujemy się w epilogu — również po odzyskaniu wolności.

Ze względu na charakter serii, jednoznacznie skierowanej do młodego czytelnika, obóz, w którym internowano rodzinę Anyi, to Spirit Lake, gdyż tylko tam obok mężczyzn umieszczano kobiety i dzieci. $Z$ dołączonego do tekstu szkicu historycznego czytelnik dowiaduje się, że obecnie jest to miejsce pamięci, w którym znajduje się upamiętniający ofiary pomnik ${ }^{32}$. Po aresztowaniu ojca cała rodzina Anyi, jak również jej sąsiedzi i najbliższy przyjaciel Stefan, trafiają do Spirit Lake. Pierwszą reakcją dziewczynki na wiadomość o internowaniu jest zwrot do pamiętnika: „Co zrobiliśmy, żeby na to zasłużyć? Czyż nie prosili nas, żebyśmy tu przyjechali? Jeśli rząd Kanady nas nie chce, to po co zachęcał nas do przyjazdu?"33. Na to pytanie nigdy nie dostanie odpowiedzi. Jednym ze strażników w obozie okazuje się Howard Smythe, biedny sąsiad Soloniuków, ukrainofob, który od początku ich pobytu w Kanadzie jawnie okazywał im niechęć i już pierwszego dnia opluł dziewczynkę i zwyzywał ją, używając obraźliwego słowa bohunk. Dzięki przyznanej mu władzy w obozie może wykorzystać swoją niechęć do byłych sąsiadów.

Jego postać pojawia się ponownie w wydanym dwa lata później opowiadaniu świątecznym An unexpected memory, którego akcja toczy się kilka lat po zakończeniu wojny. Mężczyzna traci pracę (jego poprzednie stanowisko przypada ojcu dziewczynki) i zostaje żebrakiem. Nie zważając na jego wcześniejsze postępowanie, Anya przynosi mu jedzenie. Później Smythe przeprasza za swoje przepełnione nieuzasadnioną nienawiścią zachowanie i wspólnie z rodziną Soloniuków spędza Wigilię. To bajkowe zakończenie, przywołujące na myśl Opowieść wigilijna Char-

32 P. Nora, Między pamięcia a historią. Les lieux de memoire, przeł. M. Borowski, M. Sugiera, „Didaskalia” 2011, nr 10, s. 20-27.

33 M. F. Skrypuch, Prisoners in the Promised Land. The Ukrainian Internment Diary of Anya Soloniuk, Toronto 2007, s. 124. 
lesa Dickensa, dobrze wpisuje się w charakter serii. Chociaż bohaterka zostaje internowana w obozie, w którym Ukraińcy zmuszani są do niewolniczej pracy i część z nich umiera, nigdy nie demonizuje Kanady. Gdy pisze o tym, jak bardzo chciałaby wrócić do swojej wsi, szybko to wykreśla i przeprasza pamiętnik, gdyż zdaje sobie sprawę, że i tak jest bezpieczniejsza niż jej przyjaciele w Bukowinie. Byli pracodawcy jej matki, ogarnięci poczuciem winy, wysyłają listy z prośbą o jej uwolnienie, dziewczynka wciąż dostaje też wiadomości od koleżanek, a po zwolnieniu z obozu w Montrealu czeka na nią i jej rodziców praca.

Obok prywatnej narracji Anyi w jej dzienniku można dostrzec elementy tej oficjalnej — zmieniający się stosunek władz, ale i samych Kanadyjczyków do Ukraińców. Jest to istotne zarówno dla historii Kanady, jak i Ukrainy, gdyż opowiada o pierwszej fali emigracji i próbach asymilacji przy jednoczesnym kultywowaniu tradycji i zwyczajów. Co więcej, dzięki temu, że Anya interesuje się sytuacją w ojczyźnie i dziwi ją brak zainteresowania Europą Środkową i Wschodnią w kanadyjskich przekazach dotyczących walk na froncie, czytelnik może poznać inną perspektywę dotyczącą Wielkiej Wojny. W epilogu natomiast dowiaduje się, że dzieci Anyi i Stefana nigdy nie wierzyły w internowanie, traktowały opowieści jak bajki, gdyż nie potrafiły pojąć, że tak tolerancyjny kraj jak Kanada mógł w ten sposób potraktować ich rodziców. Brak wiary wydaje się uzasadniony, szczególnie biorąc pod uwagę nieobecność świadectwa o doświadczeniu obozów w edukacji szkolnej, świadomości zbiorowej i kulturze. Chociaż według Marianne Hirsch to rodzina stanowi pokoleniową strukturę transferu postpamięci ${ }^{34}$, Alison Landsberg zauważa, że również kultura popularna może pełnić funkcję medium ją przenoszącego i tworzącego empatię ${ }^{35}$. Co więcej, jak stwierdza Anastasia Ulanowicz, literatura dziecięca ma w tym procesie szczególny potencjał ${ }^{36}$.

W przypadku internowania Ukraińców w Kanadzie można mówić o wyparciu, pokoleniowej nie-pamięci. W swoich tekstach dla najmłodszych czytelników Skrypuch oferuje medium postpamięci, zapoznając ich z wydarzeniami i bohaterami opartymi zarówno na doświadczeniach swojego dziadka, o których wreszcie opowiedział jej przy okazji pisania dziennika Anyi Soloniuk ojciec, jak i rozmowach z ocalałymi z obozu w Spirit Lake Mary Manko Haskett i Stefą Pawlik oraz Ottonem Boyko, którego ojciec był internowany. Dzięki temu teksty Skrypuch

${ }^{34}$ M. Hirsch, Pokolenie postpamięci..., s. 29.

35 Landsberg mówi o związanej z kontaktem z mediami i artefaktami pamięci protetycznej (prosthetic memory), która jest formą pośredniczącą między pamięcią jednostki a narracją historyczną. Zob. eadem, Ameryka, Holokaust i masowa kultura pamięci. W stronę radykalnej polityki empatii, przeł. P. Dobrosielski, [w:] Antropologia pamięci: zagadnienia i wybór tekstów, red. P. Majewski, M. Napiórkowski, Warszawa 2018, s. 165-172.

${ }^{36}$ Ulanowicz wprowadza termin pamięci drugiego pokolenia (second-generation memory), która „wiąże się z afirmacją, jak również poczuciem uczestnictwa we wspólnej narracji historycznej danej grupy demograficznej" - eadem, Second-generation memory and contemporary children's literature: Ghost images, New York-London 2013, s. 4. 
sprawiają, że pamięć o obozach nie tylko przetrwa, ale zostanie włączona w kanadyjską narrację dotyczącą I wojny światowej i pamięć kulturową w ogóle.

\section{Podsumowanie}

Chociaż mówiąc o pamięci zbiorowej, zazwyczaj odwołujemy się do zwycięstw, również wydarzenia haniebne można po czasie odebrać jako coś pozwalającego umocnić tożsamość narodową i pamięć wspólnoty, formułując jej pamięć kulturową ${ }^{37}$. To właśnie ona jest magazynem wiedzy o tożsamość danej wspólnoty, a jej nośnikiem może być książka. Internowanie Ukraińców w Kanadzie zostało uznane przez parlament prawie dziewięćdziesiąt lat później, prowokując dyskusję dotyczącą współczesnej polityki migracyjnej kraju. Omówione w niniejszym artykule utwory poruszają kwestię białych plam pamięci, a przywołanie ich odbioru pokazuje, jak w ciągu kilkunastu lat zmieniła się dotycząca ich oficjalna narracja. Chociaż książki autorki Enough poświęcone obozom nie są aż tak komercyjne i interesujące dla czytelnika globalnego, jak te poruszające problematykę II wojny światowej (świadczy o tym choćby ich ograniczona dostępność poza Kanadą), to ich przekład mógłby spotkać się z zainteresowaniem na Ukrainie i wpłynąć na popularyzację pamięci o I wojnie światowej, pierwszej fali kanadyjskiej migracji do Kanady i doświadczeniu internowania.

\section{Bibliografia}

Alexander J. C., Trauma kulturowa i tożsamość zbiorowa, [w:] Znaczenia społeczne. Studia z socjologii kulturowej, przeł. S. Budziej, J. Gądecki, Nomos, Kraków 2010.

Assmann A., Cztery formy pamięci, przeł. K. Sidowska, [w:] eadem, Między historia a pamięcia: antologia, red. M. Saryusz-Wolska, Wydawnictwo Uniwersytetu Warszawskiego, Warszawa 2018.

Bell K., Behind the blackout curtains: Femalefocalization of Atlantic Canada in the Dear Canada series of historical fiction, „Children's Literature in Education” 2018, $\mathrm{nr} 49$.

Branach-Kallas A., Szok Wielkiej Wojny - o traumie indywidualnej, traumie kulturowej oraz portretach gueules cassées we wspótczesnej literaturze brytyjskiej i francuskiej, „Teksty Drugie” 2018, $\mathrm{nr} 4$.

Carpenter C., In our own image: The child, Canadian culture and our future, „Children's Folklore Review" 2003, nr 25 (1-2).

Hirsch M., Pokolenie postpamięci, przeł. M. Borowski, M. Sugiera, „Didaskalia. Gazeta teatralna” 2011, nr 105.

Hubler A., Girl power and history in the Dear America series books, „Children's Literature Association Quarterly" 2000, nr 25 (3).

Kachak T., Tanatychni motyvy u suchasnij ukrainskij prozi dlja ditej ta junactva, „Slavica Wratislaviensia" 168, 2019.

Kordan B. S., Enemy Aliens, Prisoners of War: Internment in Canada during the Great War, McGill-Queen's University Press, Montreal 2002.

37 A. Assmann, Cztery formy pamięci, przeł. K. Sidowska, [w:] eadem, Między historia a pamięcią: antologia, red. M. Saryusz-Wolska, Warszawa 2018., s. 55. 
Kordan B. S., Luciuk L. Y., Creating a Landscape: A Geography of Ukrainians in Canada, Toronto 1989.

Kordan B. S., Luciuk L. Y., A Delicate and Difficult Question: Documents in the History of Ukrainians in Canada, 1899-1962, Kingstone 1986.

Kordan B. S., Mahovsky C., A Bare and Impolitic Right: Internment and Ukrainian-Canadian Redress, McGill-Queen's University Press, Montreal 2004.

LaCapra D., Doświadczenie i tożsamość, [w:] idem, Historia w okresie przejściowym. Doświadczenie, tożsamość, teoria krytyczna, przeł. K. Bojarska, Universitas, Kraków 2009.

Landsberg A., Ameryka, Holokaust i masowa kultura pamięci. W stronę radykalnej polityki empatii, przeł. P. Dobrosielski, [w:] Antropologia pamięci: zagadnienia i wybór tekstów, red. P. Majewski, M. Napiórkowski, Wydawnictwo Uniwersytetu Warszawskiego, Warszawa 2018.

Ledohowski L., Becoming the hyphen: The evolution of English-language Ukrainian-Canadian literature, „Canadian Ethnic Studies” 2007, nr 39 (1-2).

Lefebvre B., Nationalism, nostalgia, and intergenerational girlhood. Textual and ideological extensions to Laura Ingalls Wilder's Little House, [w:] Children and Cultural Memory in Texts of Childhood, red. H. Snell, L. Hutchison, Routledge, New York-London 2014.

Lehr J. C., Peopling the Prairies with Ukrainians, [w:] Canada's Ukrainians: Negotiating an Identity, red. L.Y. Luciuk, S. Hryniuk, University of Toronto Press, Toronto 1991.

Luciuk L. Y., Ukrainians in the Making: Their Kingston Story, Limestone, Kingston 1980.

Modi memorandi: leksykon kultury pamięci, red. M. Saryusz-Wolska, R. Traba, współpr. J. Kalicka, Wydawnictwo Naukowe Scholar, Warszawa 2014.

Nora P., Między pamięcia a historią. Les lieux de memoire, przeł. M. Borowski, M. Sugiera, „Didaskalia" 2011, nr 10.

Petryshyn J., Dzubak L., Peasants in the Promised Land: Canada and the Ukrainians, 1891-1914, James Lorimer, Toronto 1985.

Satzewich V., The Ukrainian Diaspora, London-New York 2002.

Skrypuch M. F., Am I Ukrainian?, [w:] Unbound: Ukrainian Canadians Writing Home, red. L. Grekul, L. Ledohowski, Scholastic, Toronto 2016.

Skrypuch M. F., An unexpected memory, [w:] A Christmas to Remember: Tales of Comfort and Joy, University of Toronto Press, Toronto 2009.

Skrypuch M. F., Prisoners in the Promised Land. The Ukrainian Internment Diary of Anya Soloniuk, Scholastic, Toronto 2007.

Skrypuch M. F., Silver Threads, Fitzhenry and Whiteside, Toronto 2004.

Smelser N. J., Psychological trauma and cultural trauma, [w:] Cultural Trauma and Collective Identity, red J. C. Alexander et al., University of California Press, Bekeley 2004.

Suchacka W., "Za Hranetsiu" - "Beyond the Border": Constructions of Identities in Ukrainian-Canadian Literature, Wissner-Verlag, Augsburg 2019.

Swyripa F., Ukrainian Canadians: A Survey of their Portrayal in English-language Works, University of Alberta Press, Edmonton 1978.

Świetlicki M., "Oh, what a waste of army dreamers...": The revolution of dignity and war in contemporary Ukrainian picturebooks, „Filoteknos” 2018, nr 8.

Świetlicki M., Mój tato zostal gwiazdą. Tanatos w ukraińskiej książce obrazkowej, „Slavica Wratislaviensia" 168, 2019.

Ulanowicz A., Second-generation memory and contemporary children's literature: Ghost images, Routledge, New York-London 2013.

Ulanowicz A., "We are the people": The Holodomor and North American-Ukrainian diasporic memory in Marsha Forchuk Skrypuch's Enough, „Miscellanea Pottotalitariana Wratislaviensia" 2017, $\operatorname{nr} 2$ (7).

Zielińska M., Wojna, trauma i kultura, „Teksty Drugie” 2018, nr 4.

Slavica Wratislaviensia 172, 2020

(C) for this edition by CNS 


\section{The terra incognita of memory. The untold history of WWI in Marsha Forchuk Skrypuch's fiction}

\section{Summary}

Ukrainian-Canadian children's author Marsha Forchuk Skrypuch has published several books about the Canadian First World War Internment. This issue first appeared in her debut picturebook Silver Threads (1996), illustrated by Michael Martchenko, then in the two texts published as part of the popular Dear Canada series, the novel Prisoners in the Promised Land. The Ukrainian Internment Diary of Anya Soloniuk (2007), and its companion Christmas story An unexpected memory (2009). Despite Skrypuch's popularity with North-American readers, her works have not been published in Ukraine and are practically unknown among Ukrainian readers and children's literature scholars. By analyzing Skrypuch's WWI-themed works, the author of this article wants to show that such texts have the potential to help young readers learn about the history of not only Canada but also Ukraine. The analysis of Skrypuch's works demonstrates that literature of the diaspora, which draws on the individual experiences of victims and witnesses of internment, can possibly serve as a medium filling in the white spots of cultural memory.

Keywords: memory, children's literature, WWI, internment, Canada, Ukraine

\section{Білі плями пам'яті. Нерозказана історія великої війни в творчості Марши Форчук Скрипух}

Резюме

Тема першої світової війни не з’являється в сучасній українській літературі для молодих читачів, хоча війна була важливою темою в радянській дитячій літературі до 1991 року. Відсутність таких публікацій дивує, враховуючи той факт, що пам'ять про своєрідний український досвід цих травматичних подій можна знайти в канадсько українській дитячій літературі, головним чином у Марши Форчук Скрипух. Незважаючи на популярність письменниці серед північноамериканських читачів, її твори не перекладені українською мовою і практично невідомі серед українських читачів і літературознавців. У цій статті я зосередився на творах на тему Першої світової війни у Скрипух і паказав, як вона ділиться „пам'яттю другого покоління” (second-generation memory) про міграцію до Канади та інтернування українців в Канаді. Застосування перспективних досліджень пам'яті дозволить мені також прочитати канадсько українську дитячу літературу як потенційне джерело „пам'яті другого покоління” для молодих українських читачів.

Ключові слова: пам'ять, дитяча література, Перша світова війна, інтернування, Канада, Україна

Slavica Wratislaviensia 172, 2020

(C) for this edition by CNS 